\title{
Correction to: Does specialist physician supply affect pediatric asthma health outcomes?
}

\author{
Guido Filler ${ }^{1,2,3^{*}}$, Tom Kovesi ${ }^{4}$, Erik Bourdon 5 , Sarah Ann Jones ${ }^{1,6}$, Laurentiu Givelichian, \\ Cheryl Rockman-Greenberg ${ }^{8}$, Jason Gilliland ${ }^{1,9}$, Marion Williams ${ }^{10}$, Elaine Orrbine ${ }^{10}$, Bruno Piedboeuf ${ }^{11}$ and The \\ Paediatric Chairs of Canada
}

\section{Correction to: BMC Health Serv Res (2018) 18: 247 https://doi.org/10.1186/s12913-018-3084-z}

In the original publication of this article [1], the institutional author's name needs to be revised from The Paediatric Chairs of Canada Mark Bernstein to The Paediatric Chairs of Canada.

\begin{abstract}
Author details
'Departments of Peediatrics, Children's Hospital at London Health Sciences Centre, University of Western Ontario, 800 Commissioners Road East, London, Ontario N6A 5W9, Canada. ${ }^{2}$ Departments of Medicine, Children's Hospital at London Health Sciences Centre, University of Western Ontario, London, Ontario, Canada. ${ }^{3}$ Departments of Pathology \& Laboratory Medicine, Children's Hospital at London Health Sciences Centre, University of Western Ontario, London, Ontario, Canada. ${ }^{4}$ Department of Pediatrics, Children's Hospital of Eastern Ontario, University of Ottawa, Ottawa, Ontario, Canada. ${ }^{5}$ The Canadian Institute for Health Information (CIHI), Ottawa, Ontario, Canada. ${ }^{6}$ Departments of Surgery, Children's Hospital at London Health Sciences Centre, University of Western Ontario, London, Ontario, Canada. 7Department of Pediatrics, University of Saskatchewan, Saskatoon, Saskatchewan, Canada. ${ }^{8}$ Department of Pediatrics and Child Health, University of Manitoba, Winnipeg, Manitoba, Canada. ${ }^{9}$ Department of Geography, University of Western Ontario, London, Ontario, Canada.

${ }^{10}$ Paediatric Chairs of Canada (PCC), Ottawa, Ontario, Canada. ${ }^{11}$ Department of Pediatrics, University Laval, Faculty of Medicine, Quebec City, Quebec, Canada.
\end{abstract}

Published online: 27 November 2019

\section{Reference}

1. Filler, et al. Does specialist physician supply affect pediatric asthma health outcomes? BMC Health Serv Res. 2018;18:247.

\footnotetext{
* Correspondence: guido.filler@lhsc.on.ca

The original article can be found online at https://doi.org/10.1186/s12913 018-3084-z

'Departments of Peediatrics, Children's Hospital at London Health Sciences Centre, University of Western Ontario, 800 Commissioners Road East, London, Ontario N6A 5W9, Canada

${ }^{2}$ Departments of Medicine, Children's Hospital at London Health Sciences

Centre, University of Western Ontario, London, Ontario, Canada

Full list of author information is available at the end of the article
}

(c) The Author(s). 2019 Open Access This article is distributed under the terms of the Creative Commons Attribution 4.0 International License (http://creativecommons.org/licenses/by/4.0/), which permits unrestricted use, distribution, and reproduction in any medium, provided you give appropriate credit to the original author(s) and the source, provide a link to the Creative Commons license, and indicate if changes were made. The Creative Commons Public Domain Dedication waiver (http://creativecommons.org/publicdomain/zero/1.0/) applies to the data made available in this article, unless otherwise stated. 